\section{FOULING EFFECTS ON REJECTION IN THE MEMBRANE FILTRATION OF NATURAL WATERS}

A.I. Schäfer ${ }^{1,2}$, A.G Fane', T.D. Waite ${ }^{2}$

1 UNESCO Centre for Membrane Science and Technology, Chemical Engineering and Industrial Chemistry, University of New South Wales, Sydney NSW 2052, Australia

A.Schaefer@unsw.edu.au; ph ++61293854470fax ++61293138624

A.Fane@unsw.edu.au; ph ++61293854315 fax ++61293855054

2 Centre for Water and Waste Technology, Civil and Environmental Engineering, University of New South Wales, Sydney NSW 2052, Australia

D.Waite@unsw.edu.au; ph ++61293855060fax ++61293856139

\section{ABSTRACT}

Membrane processes in drinking water applications are micro- (MF), ultra- (UF), and nanofiltration (NF). These processes remove turbidity and bacteria (MF), viruses and macromolecules (UF) and small molecules and hardness (NF). Of particular concern in water treatment is the removal of natural organic matter (NOM) which contains potential disinfection by-product precursors. The of natural organic matter (NOM) which contains potential disinfection by-product precursors. The
presence of colloids, multivalent ions and organics in surface waters may cause substantial fouling of presence of
membranes.

A study was carried out which looked at the rejection abilities of a range of membranes targeting hematite colloids (40-500nm), NOM and cations, fouling conditions and cost of treatment of these processes with consideration of chemical pretreatment with ferric chloride [1]. In this paper the effect of membrane fouling on rejection is presented.

The study was based on experiments with two MF membranes (GVWP, GVHP, $0.22 \mu \mathrm{m}$, Millipore), six UF membranes (1, 3, 5, 10,30,100 kDa, regenerated cellulose, Millipore), and four organic nanofiltration (NF) membranes (TFC-SR, TFC-S, TFC-ULP, CA-UF, Fluid Systems, U.S.)

Three different types of organics (IHSS humic acid, IHSS fulvic acid and an Australian concentrated NOM) in a carbonate buffer containing calcium chloride and a background electrolyte were used. Experiments were carried out in perspex (MF, UF) and stainless steel (NF) stirred cells of a volume of $110-185 \mathrm{~mL}$ and a membrane area of $15.2-21.2^{*} 10^{-4} \mathrm{~m}^{2}$ at transmembrane pressures of 1,3 , and 5 bar for MF, UF, and NF, respectively.

UF removes $10-95 \%$ of NOM depending on the molecular weight cut-off (MWCO) of the membrane. Pore sizes of $<6 \mathrm{~nm}$ are required to remove about $80 \%$ of NOM, where a $6 \mathrm{~nm}$ pore size corresponds to a MWCO of about $10 \mathrm{kDa}$. Colloids are fully rejected.

NF removes NOM effectively $(70-95 \%$ as dissolved organic carbon (DOC) and $85-98 \%$ as UV absorbance). Cation rejection is very membrane dependent and varies for the investigated membrane types between 13 and $96 \%$ for calcium and 10 to $87 \%$ for sodium.
Fouling was also dependent on pore size and was caused by large colloids $(250 \mathrm{~nm})$ or coagulant flocs in MF, small colloids, organic-calcium flocs and aggregates with a dense structure (formed slowly) in UF, and by a calcium-organic precipitate in NF. The fouling influenced the rejection of colloids in $\mathrm{MF}$ and that of NOM in UF and NF. If a highly charged layer was deposited on the NF membranes, cation rejection was also influenced. The characterisation of permeate organics revealed that low molecular weight acids passed through the NF membranes and that the rejection of these acids was also dependent on the deposit on the membrane.

The mechanisms which can explain such an increase in rejection are different for the three membrane processes. In MF, pore plugging and cake formation was found responsible for fouling. This reduces the pore size and increases rejection. In UF, internal pore adsorption of calcium-organic flocs reduces the pore size and increases rejection. In UF, internal pore adsorption of calcium-organic flocs
reduces the internal pore diameter and subsequently increases rejection. In NF, the key factor appears reduces the internal pore diameter and subsequently increases rejection. In NF, the key factor appears
to the charge of the deposit. This was investigated with the deposition of a ferric chloride precipitate. If to the charge of the deposit. This was investigated with the deposition of a ferric chloride precipitate.
the precipitate was of high positive charge, the rejection of cations increased and that of negatively charged low molecular weight acids decreased compared to more neutral or negative precipitates.

In essence, the rejection characteristics of membranes depend more on the fouling state of the membranes and the nature of the foulants than on the initial membrane characteristics.

\section{KEYWORDS}

Calcium, Fouling, Microfiltration, Nanofiltration, Ultrafiltration, Natural Organic Matter, Rejection.

\section{INTRODUCTION}

The extent of rejection of solutes by membranes is perhaps the most critical parameter in membreane filtration. For a clean (unfouled) membrane, the extent of rejection is influenced largely by the pore size solute and membrane may influence the extent of rejection. For example, unfouled MF does not retain natural organics unless they are associated with particulates due to the large pore size [2]. natural organics unless they are associated with particulates due to the large pore size [2].
Research in UF mostly focuses on size effects. Wiesner et al. [3] and Côté [4] published DOC removal as a function of molecular weight cut-off (MWCO). Wiesner et al. found a near linear decline, while Côté showed a steep decline in rejection between 1 and $10 \mathrm{kDa}$. The graphs were based on a review of publications and therefore represent the MWCO dependence well. In NF combined charge and size effects are well recognised [5]

Despite efforts to minimise the formation of deposits on membranes, fouling of the membranes however is likely to occur in many instances. This fouling process may be attributed to a number of mechanisms including pore blocking by solutes that are of similar diameter to the pores, formation of a cake from excluded solutes (i.e. solutes unable to pass through the membrane pores) and precipitation or gelation of inorganic and organic particulates at the membrane surface as a result of the localised high concentrations that occur at the membrane-solution interface. While interactions between solutes and the membranes are poorly understood, it is thought that effects like charge interactions, bridging, and hydrophobic interactions may play an important role in fouling [6].

It is clear that foulants at the membrane surface (or within the membrane pores) will exert some influence on passage of solutes through the membrane, either because the porosity of the cake or blocked membrane is lower than that of the clean membrane or because the charge properties of the fouled membrane are very different to those of the unfouled membrane.

While an effect on extent of solute rejection might be expected as a result of membrane fouling, very few studies have documented the nature or extent of this effect. The purpose of this study is to report 
on results of ordered studies into the effect of fouling on rejection by micropfiltration (MF), ultrafiltration (UF) and nanofiltration (NF) membranes.

\section{BACKGROUND}

MF, UF, and NF are pressure driven membrane processes. While the various commercial membranes are classed into process groups there is no clear boundary between these membrane classifications, rather MF, UF, NF and RO represents a continuum in 'pore size'. This is illustrated in Table 1, where sizes of water relevant solutes and particulates are compared with the range of membrane separation processes. The different processes overlap in their removal potential for various compounds.

Parameters used to quantify the efficiency of membrane processes, are flux $(\mathrm{J})$ and solute rejection $(\mathrm{R})$ where the flux is defined as

$$
J \equiv \frac{1}{A} \frac{d V}{d t}
$$

and rejection as

$$
R=100 \cdot\left(1-\frac{c_{P}}{c_{B}}\right)
$$

The Resistance in Series Model in equation (3) describes the flux of a fouled membrane. $\mathrm{R}_{\mathrm{M}}$ is the resistance of the clean membrane. The resistances $R_{C P}, R_{P}$ and $R_{C}$ denote the additional resistances which result from the exposure of the membrane to a solution containing particles or solute. $R_{\mathrm{CP}}$ is the resistance due to concentration polarisation, $\mathrm{R}_{\mathrm{P}}$ the internal pore fouling resistance, and $\mathrm{R}_{\mathrm{C}}$ the resistance due to external deposition or cake formation.

$$
J=\frac{\Delta P}{\eta\left(R_{M}+R_{C P}+R_{P}+R_{C}\right)}
$$

The nature of the resistances shows that different fouling mechanisms may operate and the distinction of these mechanism is the objective of this paper.

The effect of fouling on flux has been well documented in MF, UF and NF ([2], [7], [8]). However,

very little has been done to describe the effect of fouling on rejection.

\section{MATERIALS AND METHODS}

\subsection{Membranes, Filtration Systems and Filtration Protocol}

The membranes used were characterised in detail in other publications by Schäfer et al. [9], Aoustin et al. [10], and Schäfer et al. [8] for MF, UF, and NF, respectively. Stirred cell systems made from perspex (MF, UF) and stainless steel (NF) were used.

The filtration systems and protocols have also been described previously ([9], [10], [8]). Operating pressures are summarised in Table $2.1000 \mathrm{~mL}, 60-400 \mathrm{~mL}$, and $120 \mathrm{~mL}$ of feed solution were filtered in MF, UF and NF, respectively. Key membrane characteristics are summarised in Table 2.

\subsection{Natural Organic Matter (NOM) and Background Solution}

Three types of organics were chosen: Two of these were purified and fractionated organics, purchased from the International Humic Substances Society (IHSS), namely, Suwannee River Reference humic (HA) and fulvic (FA) acid. A third organic type, an Australian NOM was concentrated from Mooney Mooney Dam (Gosford, NSW) using microfiltration and RO to concentrate all surface water constituents. The concentrate was further freeze-dried. The NOM powder obtained includes all naturally occurring inorganic salts and hydrophilic organics, which are part of the surface water. The background solution used, contained $0.5 \mathrm{mM} \mathrm{CaCl}_{2}$ as a representative of naturally occurring multivalent cations, $1 \mathrm{mM} \mathrm{NaHCO} 3$ as a natural buffer system, and $20 \mathrm{mM} \mathrm{NaCl}$ as a background electrolyte enabling $\mathrm{pH}$ adjustment without variation of the ionic strength.

All chemicals were purchased from Ajax Chemicals (Australia). $1 \mathrm{M} \mathrm{HCl}$ and $1 \mathrm{M} \mathrm{NaOH}$ were used for $\mathrm{pH}$ adjustment, and $1 \mathrm{M} \mathrm{NaCl}$ for ionic strength adjustment.

\subsection{Analytical Methods}

Samples were characterised by UV/VIS spectrometry using a Varian Cary 1E UV/VIS. Dissolved organic carbon was analysed using a Skalar 12 carbon analyser. A Perkin Elmer Optima 3000

Inductively Coupled Plasma Atomic Emission Spectrometer (ICP-AES) was used to determine cation content of the samples. Samples were diluted with 5\% nitric acid following collection and prior to ICP analysis.

\section{RESULTS AND DISCUSSION}

\subsection{Rejection}

Rejection results are summarised in Table 3. These results are from experiments where very little or no fouling occurred. As expected (given their pore size), very little of the natural organics and none of the cations are rejected by the MF or large pore size UF membranes. The extent of rejection increases for decreasing UF pore size and reaches near complete rejection for NF. In UF, charge effects begin to play a role in the rejection of organics [11].

Results of organics rejection as a function of membrane pore size are shown in Figure 1. The lines represent the rejection of UV absorbing organics and DOC in the absence of fouling. At a pore size of about $6 \mathrm{~nm}$ (in the UF range) a distinct drop in rejection from $85 \%$ (DOC) and $95 \%$ (UV) to $10 \%$ occurs. The differ and more aromatic compounds.

\subsection{Membrane Fouling}

Fouling also depends on membrane pore size. A number of possible fouling mechanism need to be considered. Fouling may occur in pores by partial pore size reduction caused by foulants adsorbing on the inner pore walls, pore blockage and surface fouling such as cake and gel layer formation. The adsorption of compounds can also influence the hydrophilicity of a material and hence cause flux variation. Results are summarised in Table 4 for a feed containing humics and calcium and discussed in detail below.

In most water treatment applications and processes a combination of mechanisms can be expected. Foulants which are larger than the pore size will only cause surface fouling and for this reason the surface fouling becomes more important as the pore size is reduced. 


\subsubsection{Microfiltration}

Calcium-organic complexes caused considerable flux decline in MF, which confirmed findings by [12] This is most likely due to surface modification and partial pore plugging. In a previous study, colloids of a size similar to the pore size caused most severe flux decline by pore plugging and larger colloids Pake effects would be expected for larger particles such as clays and microorganisms.

\subsubsection{Ultrafiltration}

Due to the wide range of UF membranes used, pore adsorption and cake formation were observed. Calcium-organic complexes adsorbed inside the pores of the $100 \mathrm{kDa}$ membranes. This mechanism was identified by blocking law analysis [10], [13], [14].

When inorganic colloids $(75 \mathrm{~nm})$ were filtered particle interactions were important. Depending on the When inorganic colloids $(75 \mathrm{~nm})$ were filtered particle interactions were important. Depending on the
aggregation regime aggregates of different structures formed and the structure determined the extent of aggregation regime aggregates of different structures formed and the structure determined the exte
flux decline [15]. The importance of such aggregation effects was confirmed with mixed systems containing organics and aggregates. Hematite stabilised with organics and thus depositing as individual colloids caused a flux decline of $60 \%$ with the $100 \mathrm{kDa}$ membrane, while aggregated colloids caused a flux decline of only $15 \%$. Figure 2 shows the different deposits formed by (A) stable colloids and (B) aggregates. Cakes formed from individual particles (or more compact aggregates) appeared to be more compact than cakes from loosely packed aggregates. These cake characteristics reflect in flux behaviour, while issues of cake compressibility is poorly understood.

\subsubsection{Nanofiltration}

$\mathrm{NF}$ retains calcium and most of the organics. This means the concentration of these compounds is relatively high in the boundary layer and precipitation may cause severe flux decline. Large organic compounds with a smaller diffusion coefficient fouled the membranes more due to a lower solubility and higher concentration in the boundary layer [8]. Internal pore fouling was not observed. Colloids did not cause flux decline in NF, most likely due to the high colloid/pore size ratio, but did influence not cause flux decline in $\mathrm{NF}$,
rejection as discussed below.

\subsection{Effect of Fouling on Rejection}

Two effects of fouling on rejection were observed; first an increase in rejection due to a reduction of membrane pore size and second a modification of the separation behaviour of the membranes due to the deposit. This modification resulted in increase or decrease in rejection in particular instances. The increase in rejection with fouling is shown as a function of pore size in Figure 1. The cut-off of about $6 \mathrm{~nm}$ where rejection drops for unfouled membranes is now increased to $>20 \mathrm{~nm}$. This is dominated by effects in the UF range, where internal pore adsorption was predominant as shown by Aoustin et al. [10]. The deposit also modified rejection behaviour and depending on the process different solution compounds were responsible (as shown below).

\subsubsection{Microfiltration}

In MF, particles of a size very similar to the pore size, blocked pores and subsequently prevented further particles passing through the membrane [9]. This effect is a very direct sieving phenomena.

\subsubsection{Ultrafiltration}

The influence of the deposit was also observed in UF where the structure of a deposit of inorganic colloids could modify the rejection of an organic. This is shown in Figure 3. The tight cake structure produced from relatively stable colloids retains far more of the organics than the loose structure (produced from aggregates formed under diffusion limited conditions), but both inorganic cakes retain organics effectively as the rejection of the cake-free membrane is $<10 \%$. The relation between aggregate structure and effect on membrane flux is described in detail by Waite et al. [15].

\subsubsection{Nanofiltration}

In NF, the effect of rejection variation by fouling was confirmed by two different types of experiments.

Firstly, when the membrane was fouled with a calcium-organic deposit as described by Schäfer et al.
[8], fouling increased the rejection of organics by up to $20 \%$. Secondly, ferric chloride salt was added to remove foulants and inhibit precipitation of a calcium-organic gel layer. In this case a ferric hydroxide precipitate deposited on the membrane. While this prevented flux decline, the rejection behaviour was modified strongly. This is shown in Table 5. The variation of rejection was in this case attributed to the formation of deposits of a different charge. The high ferric chloride dose lead to a positively charged deposit and thus an increase in rejection for the cations and a decrease for the negatively charged organics. The lower rejection for the organics may have also been due to raised concentrations in the unstirred cake layer.

\section{CONCLUSIONS}

The study of three membrane processes which are widely used in water treatment, MF, UF, and NF, showed that fouling significantly influences membrane rejection behaviour. A reduction in pore size by pore adsorption and pore plugging increased rejection, while deposits on NF membranes can also decrease rejection of some compounds. A pore size to foulant size ratio was important in the determination of the mechanisms involved in rejection and fouling.

\section{ACKNOWLEDGEMENTS}

Fluid Systems (San Diego, U.S.) are thanked for providing membrane samples, Millipore Australia for materials support and the CRC for Water Quality and Treatment for project funding. E. Aoustin, U. Schwicker and M. Fischer are acknowledged for assistance with experimental work.

\section{REFERENCES}

[1] A. I. Schäfer, "Natural Organic Matter Removal using Membranes," in Chemical Engineering. Sydney, Australia: University of New South Wales, 1999.

[2] W. Yuan and A. L. Zydney, "Humic acid fouling during microfiltration," Journal of Membrane Science, vol. 157, pp. 1-12, 1999 .

[3] M. R. Wiesner, M. M. Clark, J. G. Jacangelo, B. W. Lykins, B. J. Marinas, C. R. O'Melia, B. E Rittmann, and M. J. Semmens, "Committee report: membrane processes in potable water treatment," Journal $A W W A$, vol. Jan, pp. 59-67, 1992.

[4] P. Côté, "State-of-the-art techniques in reverse osmosis, nanofiltration and electrodialysis in drinking-water supply," presented at 20th International Water Supply Congress \& Exhibition IWSA, Durban, South Africa, 1995.

[5] J. M. M. Peeters, M. H. V. Mulder, K. Keizer, H. Strathmann, and H. Verweij, "Streaming potential measurements as a characterisation method for nanofiltration membranes," presented at Proc. of Colloid Science in Membrane Engineering, Toulouse, France, 1996.

[6] J. Baker, T. Stephenson, S. Dard, and P. Côté, "Characterisation of fouling of nanofiltration membranes used to treat surface waters," Environmental Technology, vol. 16, pp. 977-985, 1995.

[7] E. Matthiasson, "The role of macromolecular adsorption in fouling of ultrafiltration membranes," Journal of Membrane Science, vol. 16, pp. 23-36, 1983.

[8] A. I. Schäfer, A. G. Fane, and T. D. Waite, "Nanofiltration of natural organic matter: removal, fouling and the influence of multivalent ions," Desalination, vol. 118, pp. 109-122, 1998.

[9] A. I. Schäfer, U. Schwicker, M. M. Fischer, A. G. Fane, and T. D. Waite, "Microfiltration of Colloids and Natural Organic Matter," Journal of Membrane Science, vol. 171, pp. 151-172, 2000.

[10] E. Aoustin, A. I. Schäfer, A. G. Fane, and T. D. Waite, "Effect of Humic Sustance and Colloid Interactions on Ultrafiltration Behaviour," Separation and Purification Technology, vol. (in press), 2000.

[11] A. I. Schäfer, R. Mauch, A. G. Fane, and T. D. Waite, "Charge effects in the fractionation of natural organics using ultrafiltration," Environmental Science \& Technology, (in preparation). 
Schäfer, A.I. ; Fane, A.G. ; Waite, T.D. (2000) Fouling Effects on Rejection in the Membrane Filtration of Natural Waters, Desalination (2000) 131, 1-3, 215-224.

[12] W. Yuan and A. L. Zydney, "Effects of Solution Environment on Humic Acid Fouling during Microfiltration," Desalination, vol. 122, pp. 63-76, 1999.

[13] J. Hermia, "Constant pressure blocking filtration laws-application to power-law non-newtonian fluids," Trans IChemE, vol. 60, pp. 183-187, 1982.

[14] W. R. Bowen, J. I. Calvo, and A. Hernández, "Steps of membrane blocking in flux decline during protein microfiltration," Journal of Membrane Science, vol. 101, pp. 153-165, 1995.

[15] T. D. Waite, A. I. Schäfer, A. G. Fane, and A. Heuer, "Colloidal Fouling of Ultrafiltration Membranes: Impact of Aggregate Structure and Size," Journal of Colloid and Interface Science, vol. 212, pp. 264-274, 1999

[16] M. Cheryan, Ultrafiltration Handbook. USA: Technomic Publishing Company, Inc., 1986.

[17] M. K. A. Agbekodo, "Élimination par nanofiltration des composés organiques d'une eau de surface prétraité. Caractérisation du carbone organique dissous avant et après nanofiltration,” Poitiers, France: Université de Poitiers, 1994.

[18] E. Worch, "Eine neue Gleichung zur Berechnung von Diffusionskoeffizienten gelöster Stoffe," Vom Wasser, vol. 81, pp. 289-297, 1993.

\section{SYMBOLS}

A: $\quad$ Membrane Surface $\left[\mathrm{m}^{2}\right]$

Feed Concentration $\left[\mathrm{mgL}^{-1}\right]$

Permeate Concentration $\left[\mathrm{mgL}^{-1]}\right.$

Flux $\left[\mathrm{Lm}^{-2} \mathrm{~h}^{-1}\right.$

Pure Water Flux prior to Experiment $\left[\mathrm{Lm}^{-2} \mathrm{~h}^{-1}\right]$

Pure Water Flux after Experiment $\left[\mathrm{Lm}^{-2} \mathrm{~h}^{-1}\right]$

Rejection [\%] Prope

Membrane Resis

external deposition or cake formation $\left[\mathrm{m}^{-1}\right]$

Rembrane Resistance due to concentration Polarisation $\left[\mathrm{m}^{-1}\right]$

clean Membrane $\left[\mathrm{m}^{-1}\right.$

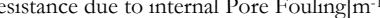

Permeate Volume [L]

$\eta$ V: $\quad$ Viscosity of Solvent (water) [Pa s]

\section{TABLES}

Table 1 Overview of membrane treatment processes and solute/particle dimensions ([16], [17]).

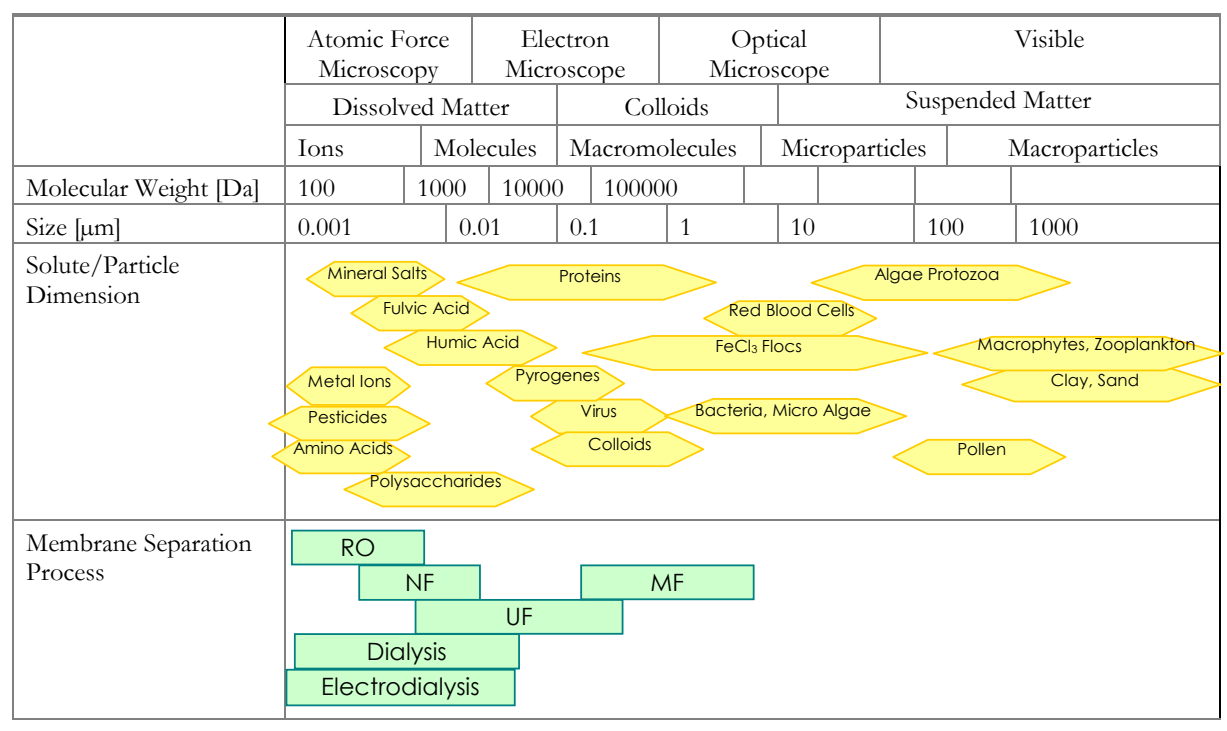


Schäfer, A.I. ; Fane, A.G. ; Waite, T.D. (2000) Fouling Effects on Rejection in the Membrane Filtration of Natural Waters, Desalination (2000) 131, 1-3, 215-224.

doi:10.1016/S0011-9164(00)90020-1

Table 2 Pure water membrane characteristics of the membranes used.

\begin{tabular}{|c|c|c|c|c|c|c|c|}
\hline Process & Membrane & $\begin{array}{c}\text { Pure Water } \\
\text { Flux } \\
{\left[\mathrm{Lm}^{-2} \mathrm{~h}^{-1}\right]}\end{array}$ & $\begin{array}{c}\text { Water } \\
\text { Permeability } \\
{\left[\mathrm{Lm}^{-2} \mathrm{~h}^{-1} \mathrm{bar}^{-1}\right]}\end{array}$ & $\begin{array}{c}\text { Pressure } \\
\text { [bar] }\end{array}$ & $\begin{array}{c}\text { Membrane } \\
\text { Resistance } \\
{\left[\mathrm{m}^{-1}\right]}\end{array}$ & $\begin{array}{c}\text { MWCO } \\
{[\mathrm{kDa}]}\end{array}$ & $\begin{array}{c}\text { Pore } \\
\text { Diameter } \\
{[\mathrm{nm}]}\end{array}$ \\
\hline MF & GVWP & $7968 \pm 288$ & 7968 & 1 & $4.51 \cdot 10^{7}$ & - & $220^{*}$ \\
\hline MF & GVHP & $7803 \pm 308$ & 7803 & 1 & $4.60 \cdot 10^{7}$ & & $220^{*}$ \\
\hline UF & PLHK & $1320 \pm 40$ & 1320 & 1 & $0.03 \cdot 10^{10}$ & $100^{*}$ & $18.20^{\mathrm{s}}$ \\
\hline UF & PLTK & $390 \pm 20$ & 390 & 1 & $0.09 \cdot 10^{10}$ & $30^{*}$ & $9.62^{\mathrm{s}}$ \\
\hline UF & PLGC & $65 \pm 5$ & 21.7 & 3 & $1.66 \cdot 10^{10}$ & $10^{*}$ & $5.18^{s}$ \\
\hline UF & PLCC & $28 \pm 3$ & 9.3 & 3 & $3.85 \cdot 10^{10}$ & $5^{*}$ & $3.72^{\mathrm{s}}$ \\
\hline UF & PLBC & $22 \pm 2$ & 7.3 & 3 & $4.90 \cdot 10^{10}$ & $3^{*}$ & $2.84^{\mathrm{s}}$ \\
\hline UF & PLAC & $15 \pm 2$ & 5.0 & 3 & $7.18 \cdot 10^{10}$ & $1^{*}$ & $1.88^{\mathrm{s}}$ \\
\hline $\mathrm{NF}$ & CA-UF & $49.9 \pm 4.2$ & 10.0 & 5 & $3.6 \cdot 10^{10}$ & $5^{\#}$ & $3.72^{\mathrm{s}}$ \\
\hline NF & TFC-SR & $45.8 \pm 6.1$ & 9.2 & 5 & $3.9 \cdot 10^{10}$ & $<0.18^{\#}$ & $<0.64^{\mathrm{s}}$ \\
\hline $\mathrm{NF}$ & TFC-S & $49.4 \pm 5.9$ & 9.9 & 5 & $3.6 \cdot 10^{10}$ & $<0.18^{\#}$ & $<0.64^{\mathrm{s}}$ \\
\hline $\mathrm{NF}$ & TFC-ULP & $19.4 \pm 2.6$ & 3.9 & 5 & $9.3 \cdot 10^{10}$ & $<0.18^{\#}$ & $<0.64^{\mathrm{s}}$ \\
\hline
\end{tabular}

information supplied by Millipore.

ing lactose marker tests. Rejections for MWCO as $>90 \%$ at $1 \%$

glucose in MilliQ. CA-UF determined with $5 \mathrm{kDa}$ dextran at $100 \mathrm{mgL}^{-1}$. Rejection of $10 \mathrm{kDa}$ dextran was $76 \%$ (Takigawa (19)

Table 3 Rejection of DOC, UV absorbance at $254 \mathrm{~nm}$ and cations as a function of membrane at $\mathrm{pH} 7-$ $8,5-15 \mathrm{mgL}^{-1}$ organics as DOC, $0.5 \mathrm{mM} \mathrm{CaCl}_{2}$. Cation rejection is in the absence of organics.

\begin{tabular}{lcccccccc}
\hline & \multicolumn{9}{c}{ DOC Rejection [\%] / UV 254 Rejection [\%] } & \multicolumn{3}{c}{ Rejection [\%] } \\
\hline & IHSS & IHSS & NOM & NOM & NOM & NOM & $\mathrm{Ca}^{2+}$ & $\mathrm{Na}^{+}$ \\
& HA & FA & & HA & FA & Hyd & & \\
\hline MF GVWW & $10 / 4^{\#}$ & $7 / 0^{\#}$ & $17 / 2^{\#}$ & - & - & - & 0 & 0 \\
UF 100 kDa & $6 / 4$ & $8 / 4^{\#}$ & $9 / 9^{\#}$ & $8 / 5^{\#}$ & $3 / 4^{\#}$ & $4 / 5^{\#}$ & 0 & 0 \\
UF 30 kDa & $11 / 12$ & $12 / 13$ & $10 / 8$ & $2 / 7$ & $0 / 4$ & $14 / 26$ & 2.8 & 0 \\
UF 10 kDa & $66 / 88$ & $56 / 53$ & $51 / 55$ & $65 / 76$ & $58 / 64$ & $41 / 50$ & 2.6 & 0 \\
UF 5 kDa & $88 / 91$ & $82 / 63$ & $74 / 71$ & $79 / 87$ & $77 / 81$ & $60 / 66$ & 2.0 & 0 \\
UF 3 kDa & $86 / 93$ & $84 / 94$ & $77 / 73$ & $79 / 90$ & $78 / 86$ & $60 / 73$ & 13.6 & 0 \\
UF 1 kDa & $90 / 96$ & $87 / 97$ & $86 / 84$ & $82 / 79$ & $81 / 89$ & $68 / 80$ & 13.2 & 0 \\
NF CA-UF & $76 / 83$ & $71 / 91$ & $57 / 72$ & - & - & - & 14.4 & 12.6 \\
NF TFC-SR & $74 / 97$ & $94 / 96$ & $69 / 97$ & $96 / 99^{\#}$ & $96 / 98^{\#}$ & $84 / 87^{\#}$ & 67.6 & 37.4 \\
NF TFC-S & $90 / 99$ & $84 / 95$ & $95 / 96$ & - & - & - & 94.4 & 82.0 \\
NF TFC-ULP & $76 / 99$ & $80 / 88$ & $95 / 96$ & - & - & - & 90.4 & 85.0 \\
\hline
\end{tabular}

values are at $2.5 \mathrm{mM} \mathrm{CaCl}_{2}, 5-15 \mathrm{mgL}^{-1}$ organics as DOC. Rejection of IHSS HA at these conditions is

$92.7 \%$ (TFC-SR) and $57 \%$ (UF $100 \mathrm{kDa}$ ), for comparison.
Table 4 Flux, flux decline, permeability, membrane resistance and rejection at $2.5 \mathrm{mM} \mathrm{CaCl}_{2}$ and IHSS $\mathrm{HA}$ at $\mathrm{pH} 7-8$.

\begin{tabular}{|c|c|c|c|c|c|c|c|c|c|}
\hline \multirow[b]{2}{*}{ Process } & \multicolumn{5}{|c|}{ Flux } & \multicolumn{4}{|c|}{ Rejection } \\
\hline & $\begin{array}{c}\mathrm{JF}_{\mathrm{F}} \\
{\left[\mathrm{Lm}^{-2} \mathrm{~h}^{-1}\right]}\end{array}$ & $\begin{array}{c}\mathrm{J}_{\mathrm{F}} / \mathrm{J}_{0} \\
{[-]}\end{array}$ & $\begin{array}{c}\mathrm{LF}_{\mathrm{F}} \\
{\left[\mathrm{Lm}^{-2} \mathrm{~h}^{-1} \mathrm{bar}^{-1}\right]}\end{array}$ & $\begin{array}{c}\mathrm{R}_{\mathrm{M}} \\
{\left[10^{10} \mathrm{~m}^{-1}\right]}\end{array}$ & $\begin{array}{c}\mathrm{R}_{\mathrm{F}} \\
{\left[10^{10} \mathrm{~m}^{-1}\right]}\end{array}$ & $\begin{array}{c}\text { DOC } \\
{[\%]}\end{array}$ & $\begin{array}{c}\mathrm{UV}_{254} \\
{[\%]}\end{array}$ & $\begin{array}{l}\mathrm{Ca}^{2+} \\
{[\%]}\end{array}$ & $\begin{array}{l}\mathrm{Na}^{+} \\
{[\%]}\end{array}$ \\
\hline MF GVWP & 1732 & 0.22 & 1732 & 0.0046 & 0.0162 & 10 & 4 & 0 & 0 \\
\hline MF GVHP & 1981 & 0.25 & 1981 & 0.0045 & 0.0181 & 16 & 6 & 0 & 0 \\
\hline UF $100 \mathrm{kDa}$ & 76 & 0.12 & 76 & 0.057 & 0.416 & 57 & 70 & 0 & 0 \\
\hline UF $10 \mathrm{kDa}$ & 32 & 0.94 & 11 & 3.168 & 0.198 & 70 & 87 & 6 & 4 \\
\hline NF CA-UF & 41 & 0.83 & 8 & 3.600 & 0.780 & 74 & 89 & 98 & 20 \\
\hline NF TFC-SR & 34 & 0.75 & 7 & 3.920 & 1.360 & 93 & 100 & 96 & 24 \\
\hline NF TFC-S & 19 & 0.39 & 4 & 3.625 & 5.815 & 94 & 99 & 55 & 80 \\
\hline NF TFC-ULP & 12 & 0.61 & 2 & 9.255 & 5.710 & 87 & 98 & 21 & 91 \\
\hline
\end{tabular}

Table 5 Rejection as a function of organic type and $\mathrm{FeCl}_{3}$ concentration $\left(25 \mathrm{mgL}^{-1} \mathrm{FeCl}_{3}\right.$ or $100 \mathrm{mgL}^{-1}$ $\mathrm{FeCl}_{3}$, TFC-SR, $\left.5 \mathrm{mgL}^{-1} \mathrm{DOC}\right)$.

\begin{tabular}{lcccc}
\hline & DOC [\%] & UV $_{254 n m}[\%]$ & Calcium [\%] & Sodium [\%] \\
\hline $0 \mathrm{FA}$ & 94 & 96 & 68 & 36 \\
\hline $0 \mathrm{HA}$ & 74 & 98 & 63 & 19 \\
\hline $0 \mathrm{NOM}$ & 69 & 97 & 74 & 40 \\
\hline 25 FA & 72.4 & 94.6 & 44.3 & 0 \\
\hline $25 \mathrm{HA}$ & 69.4 & 93.8 & 71.2 & 0 \\
\hline $25 \mathrm{NOM}$ & 68.8 & 96.7 & 63.4 & 0 \\
\hline $100 \mathrm{FA}$ & 45.1 & 99.7 & 96.1 & 31.2 \\
\hline $100 \mathrm{HA}$ & 45.9 & 98.4 & 93.2 & 31.4 \\
\hline $100 \mathrm{NOM}$ & 47.6 & 96.8 & 93.7 & 21.9 \\
\hline
\end{tabular}


FIGURES

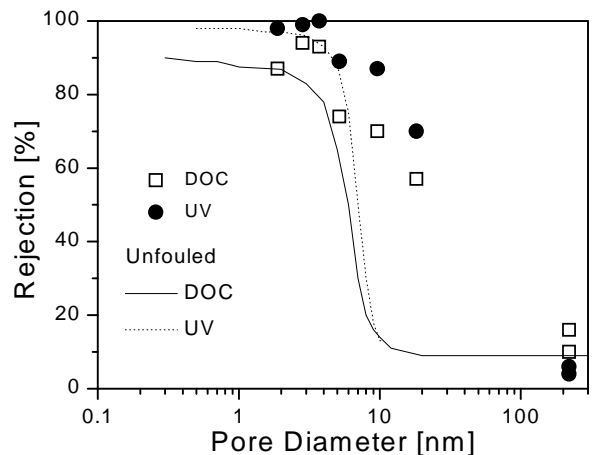

Figure 1 Rejection at fouling conditions as a function of pore diameter. The line graphs are rejection of unfouled membranes. Experimental conditions $2.5 \mathrm{mM} \mathrm{CaCl}_{2}$ and IHSS HA at pH 7-8. Pore diameter as shown in Table 1.
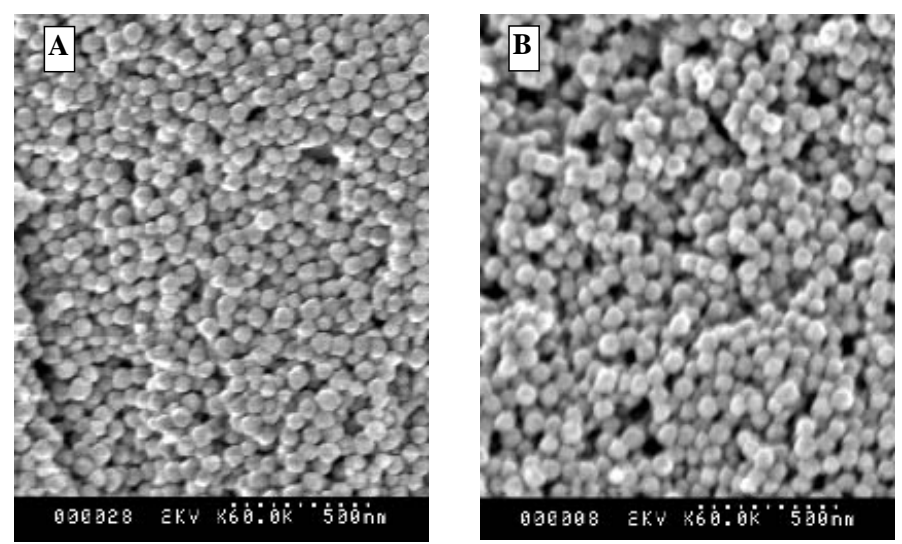

Figure 2 Electronmicrographs of deposits on the $100 \mathrm{kDa}$ membranes of (A) OPS and (B) SPO systems $\left(12.5 \mathrm{mgL}^{-1}\right.$ as DOC IHSS HA, pH 7-8, $10 \mathrm{mgL}^{-1}$ hematite, primary colloid size $75 \mathrm{~nm}$, in background solution).

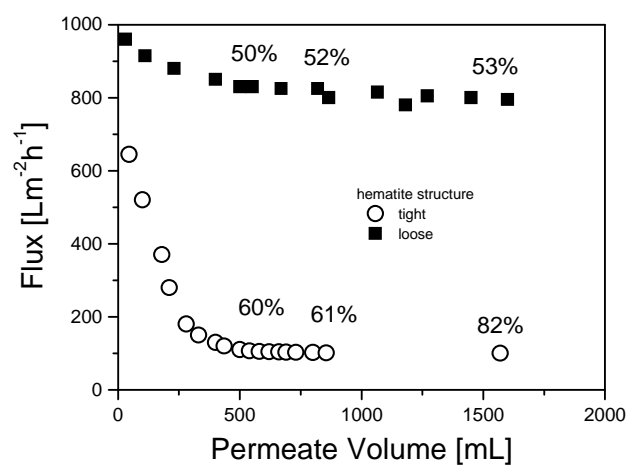

Figure 3 Permeate flux versus permeate volume during UF of humic acid solution with loose or compact structured aggregate coating of the membrane (100 kDa membrane, $5 \mathrm{mgL}^{-1} \mathrm{HA}$ as DOC, $\mathrm{pH}$ $7-8$, hematite deposition at $\mathrm{pH} 3$ with $40 \mathrm{mM} \mathrm{KCl}$ (tight structure) and $80 \mathrm{mM} \mathrm{KCl}$ (loose structure)). 